\title{
Comparison of Meta-Cognitive Beliefs with Regard to Depressed, Obsessive-Compulsive and Normal Individuals
}

\author{
Niknaz Salehi Moghadam, Khadijeh Abolmaali*, Mina Mojtabaie \\ Department of psychology, Islamic Azad University Roudehen Branch, Tehran, Iran \\ Email: sama.abolmaali@gmail.com
}

Received 29 May 2014; revised 9 July 2014; accepted 22 July 2014

Copyright (C) 2014 by authors and Scientific Research Publishing Inc.

This work is licensed under the Creative Commons Attribution International License (CC BY). http://creativecommons.org/licenses/by/4.0/

(c) (i) Open Access

\begin{abstract}
The main purpose of the present study was to investigate and compare the meta-cognitive beliefs of three groups consisting of depressed, obsessive-compulsive and normal individuals. This expost facto study was carried out on 174 individuals (58 depressed, 58 obsessive-compulsive, and 58 normal). The depressed and obsessive-compulsive patients were selected from psychological clinics in central and southern Tehran using purposive sampling. The normal group was randomly selected from the staff of the related clinics. Participants completed three questionnaires including the Beck Depression Inventory-II (BDI-II), the Maudsley Obsessive-Compulsive Inventory (MOCI), and the Meta-CognitionsQuestionnaire-30 (MCQ-30). The MANOVA test was used to analyze the statistical data. There were significant differences between the mean scores with regard to the meta-cognitive beliefs in normal individuals and in patients with depression or obsessivecompulsive disorders. Furthermore, with regard to cognitive confidence and cognitive self-consciousness subscales, there were significant differences between depressed and obsessive-compulsive patients. The mean scores of these two subscales were higher in obsessive-compulsive patient, in comparison with depressed individuals. There was no significant difference between the depressed and obsessive-compulsive groups regarding the three subscales of positive beliefs about worry, uncontrollability and need to control thoughts.
\end{abstract}

\section{Keywords}

Meta-Cognitive Beliefs, Depression, Obsessive-Compulsive

\section{Introduction}

The study of meta-cognition was initially established in relation to developmental psychology and then it was "Corresponding author.

How to cite this paper: Salehi Moghadam, N., Abolmaali, K.H. and Mojtabaie, M. (2014) Comparison of Meta-Cognitive Beliefs with Regard to Depressed, Obsessive-Compulsive and Normal Individuals. Health, 6, 1662-1668. 
conducted in relation to the memory, elderly and neuropsychology areas [1]. Although distinguishing between cognition and meta-cognition is difficult [2], researchers have provided various definitions of meta-cognition. The term "meta-cognition" was first used by Flovel [3] and defined as "thinking about thinking”. In recent years, meta-cognition has received attention as the cause of psychological disorders [4] [5]. Meta-cognition relates to the knowledge that is involved in assessing, monitoring, and controlling cognition. It includes all cognitive information and some specific meta-cognitive aspects that are related to psychological disorders. Most cognitive activities depend on the meta-cognitive factors that monitor and control such activities [5].

According to meta-cognition theory, meta-cognitive beliefs direct the attention, determine the thinking style, and lead to the coping responses that cause the production of unhelpful information. The theory also suggests the existence of meta-cognitive beliefs alongside other stored beliefs about the self and the world, but as a separate part that is responsible for controlling cognition and the use of other beliefs and general knowledge [6]. Meta-cognitive beliefs consist of five subscales: positive beliefs about worry, negative beliefs about uncontrollability and danger of worry, cognitive confidence, the need to control thoughts, and cognitive self-consciousness. Based on meta-cognition theory, disturbances in thinking and emotion result from meta-cognitive beliefs that differ from the thoughts and beliefs that are emphasized in cognitive-behavioural therapy (CBT). While in cognitive-behavioural theories, the content of thoughts is the determining factor in the presence of disorder, according to meta-cognition theory, how we think about an internal event can cause emotional suffering. An important aspect of this theory is that the meta-cognitive factors have a determining role in producing useless thinking styles that lead to the persistence of negative emotions. The difference between meta-cognitive therapy and cognitive-behavioural therapy is that what cognitive-behavioural therapists identify as the cause of a disorder, is not known as the cause in meta-cognitive therapy. The meta-cognitive approach claims that the content of the individual's thoughts is not the cause of the disorder; instead, the cause is related to the meta-cognitive beliefs that have formed thinking styles. Such thinking styles entrap individuals in persistent conditions of negative self-processing. In fact, the meta-cognitive approach investigates the factors that lead to the formation of unhelpful persistent thinking styles [6]. Meta-cognitive therapy is based on the fact that psychological disorder is related to the activation of a particular toxic thinking style that is called cognitive-attentional syndrome (CAS).

Depression and obsession are among the disorders associated with emotional disturbance [5]. Depression is the most prevalent psychological disorder. The prevalence of depression among women is twice that of men. Obsessive-compulsive disorder is the fourth most common psychological disorder, with a lifetime prevalence of $2 \%-3 \%$ in the general population. The incidence of this disorder is equal among men and women [7].

Rachman and De Silva [8] reported that $90 \%$ of normal individuals have experienced intrusive thoughts, images, and impulses which are similar to those experienced by obsessive patients in terms of their form and content. However, the interpretation of obsessive patients with regard to intrusive thoughts differs from that of normal individuals.

Positive meta-cognitive beliefs cause an increase in sustained brooding on the meaning and causes of symptoms, and one's life circumstances. This leads to prolonged and intensified depressive symptoms. This effect is important in continuing mood disturbances. Due to the persistence of symptoms and psychological factors, negative meta-cognitive beliefs are activated. These beliefs play a role in the persistence of rumination and unhelpful coping strategies; because the person believes that he does not have any control over his beliefs [6].

Due to the crucial role of meta-cognitive beliefs in the changing, persistence, and treatment of depression and obsessive-compulsive disorders [9], carrying out of the present study was seen to be important. The aim of this study was to compare the meta-cognitive beliefs on the part of depressed, obsessive-compulsive and normal individuals.

\section{Method}

\subsection{Procedure}

This research was an ex post facto study. The statistical population consisted of 174 individuals (58 depressed, 58 obsessive-compulsive, and 58 normal). Depressed and obsessive-compulsive patients were purposefully selected from men and women between 25 to 50 years of age who had been referred to psychological clinics in central and southern Tehran between 2012 and 2013. The normal group was randomly selected from the clinics' staff within the same age range. The mean age of the participants was 35.05. Of the 174 studied individuals, $63.2 \%$ were female and $36.8 \%$ were male. According to their level of education, $37.9 \%$ had a high-school dip- 
loma, 48.9\% had a bachelor's degree, and 13.2\% had a master's degree.

All patients were first examined by a psychologist. The Beck Depression Inventory-II (BDI-II) and the Maudsley Obsessive-Compulsive Inventory (MOCI) were used to diagnose depression and obsessive-compulsive disorders, respectively. The Meta-Cognition Questionnaire-30 (MCQ-30) was used to compare the metacognitive beliefs of the three groups of participants. The MANOVA test was for used statistical analysis.

\subsection{Instruments}

\subsubsection{Meta-Cognitions Questionnaire-30 (MCQ-30)}

The MCQ-30 [10] is a self-report questionnaire containing 30 questions. Each answer is scored on a 4-point Likert scale ranging from 1 (do not agree) to 4 (agree very much). The MCQ-30 assesses the five subscales of meta-cognitive beliefs including positive beliefs, uncontrollability and danger, cognitive confidence, the need to control thoughts, and cognitive self-consciousness. In Iran, the Cronbach's alpha was reported to be 0.91 for the total scale, and ranged from 0.71 to 0.87 for the subscales. The test-retest reliability was 0.73 after a four-week period for the total scale, and ranged from 0.59 to 0.83 for the subscales [11].

\subsubsection{Beck Depression Inventory-II (BDI-II)}

The BDI was first constructed in 1961 [12]. The BDI contains 21 items. Each item is scored on a 4-point scale $(0$ - 3). The total score ranges from 0 to 63 . The BDI is sensitive to treatment effects and has a high level of reliability [13]. Individuals with a score of above 15 were considered as being depressed.

\subsubsection{Maudsley Obsessive-Compulsive Inventory (MOCI)}

The MOCI was designed by Rachman and Hodgson [14] in order to assess the obsessive-compulsive behaviours in the areas of contamination checking, cleaning, slowness, and doubting. The primary validation was carried out at Maudsley Hospital. The questionnaire has a true-false format and contains 30 items. The total score ranges from 0 to 30. Scores of 0 - 5 indicate normal behaviour, 6 - 10 obsession-compulsive tendency, 11 - 15 mild obsession, 16 - 20 moderate obsession, 21 - 25 severe obsession and 26 - 30 very severe obsession. The validity of the MOCI for clinical samples in different countries has been confirmed.

\section{Results}

All variables were assessed for normality. All the measures in the depressed and obsessive-compulsive groups had normal distributions. In the normal group, the two variables of positive beliefs about worry and uncontrollability and danger were not distributed normally. The remaining variables in this group had normal distributions. Table 1 shows the descriptive data on the scores for meta-cognitive beliefs and their five subscales in depressed, obsessive-compulsive, and normal individuals.

The research hypothesis was that there are differences between meta-cognitive beliefs of depressed, obsessive-compulsive and normal individuals. To test the research hypothesis, multivariate analysis of variance (MANOVA) was used.

According to Table 2, the assumption of homogeneity of the variance-covariance matrix was rejected, and therefore the Pillai's trace was used to test the hypothesis.

Table 3 shows the summary of multivariate analyses. By considering the results of multivariate analyses, especially the Pilai's trace (1.013), F (34.504), and degrees of freedom (336 and 10), the zero hypothesis was rejected $(p<0.01)$. In other words, the mean total score of the meta-cognitive beliefs subscales of the normal group had a significant difference compared with those of the depressed and obsessive-compulsive groups. Thus, based on the subscales of the meta-cognitive beliefs, depressed, obsessive-compulsive, and normal groups can be distinguished.

According to the results of the effect tests between subjects (Table 4), it can be concluded that there was a significant difference between the mean scores in terms of the meta-cognitive beliefs subscales in depressed, obsessive-compulsive and normal individuals. Hence, there was sufficient evidence to accept the research hypothesis. The total mean score of meta-cognitive beliefs was 82.2 in depressed, 82.6 in obsessive-compulsive, and 52.06 in normal individuals.

As Table 5 shows, with regard to each of the five subscales of meta-cognitive beliefs, there were significant differences between normal individuals and the two groups of depressed and obsessive-compulsive patients. The 
Table 1. Score of meta-cognitive beliefs in study participants.

\begin{tabular}{|c|c|c|c|c|c|c|c|}
\hline \multirow{2}{*}{ Variable } & \multicolumn{7}{|c|}{ Descriptive indices } \\
\hline & Subscales & Mean & $\begin{array}{l}\text { Standard } \\
\text { deviation }\end{array}$ & Skewness & Kurtosis & $\begin{array}{l}\text { Standard error } \\
\text { of kurtosis }\end{array}$ & Sig \\
\hline \multirow[t]{6}{*}{$\begin{array}{l}\text { Meta-cognitive beliefs } \\
\text { of depressed people }\end{array}$} & Positive beliefs about worry & 15.53 & 3.29 & -0.206 & -0.124 & 1.084 & 0.190 \\
\hline & Uncontrollability and danger & 18.34 & 3.45 & -0.206 & 0.957 & 0.879 & 0.422 \\
\hline & Cognitive confidence & 16.15 & 3.77 & -0.622 & -0.345 & 1.330 & 0.058 \\
\hline & Need to control thoughts & 16.17 & 2.84 & -0.499 & 0.415 & 1.133 & 0.153 \\
\hline & Cognitive self-consciousness & 16.01 & 3.32 & -0.298 & 0.383 & 0.530 & 0.942 \\
\hline & Meta-cognitive beliefs (total score) & 82.22 & 11.77 & -0.341 & 0.349 & 1.251 & 0.088 \\
\hline \multirow[t]{6}{*}{$\begin{array}{l}\text { Meta-cognitive beliefs } \\
\text { of obsessive people }\end{array}$} & Positive beliefs about worry & 15.67 & 3.21 & -0.553 & -0.344 & 1.076 & 0.197 \\
\hline & Uncontrollability and danger & 18.67 & 2.46 & -0.553 & 1.417 & 1.321 & 0.061 \\
\hline & Cognitive confidence & 12.89 & 3.95 & -0.807 & -0.685 & -0.863 & 0.445 \\
\hline & Need to control thoughts & 17.34 & 2.65 & 0.187 & -0.7610 & 1.004 & 0.266 \\
\hline & Cognitive self-consciousness & 18.03 & 2.48 & -0.200 & -0.265 & 0.835 & 0.488 \\
\hline & Meta-cognitive beliefs (total score) & 82.62 & 8.99 & -0.154 & -0.576 & 0.571 & 0.900 \\
\hline \multirow[t]{6}{*}{$\begin{array}{l}\text { Meta-cognitive beliefs } \\
\text { of normal people }\end{array}$} & Positive beliefs about worry & 8.01 & 1.86 & -0.008 & 4.573 & $1.576^{*}$ & 0.014 \\
\hline & Uncontrollability and danger & 9.96 & 2.11 & 1.646 & -0.151 & $1.601^{*}$ & 0.012 \\
\hline & Cognitive confidence & 9.68 & 2.16 & 0.585 & 2.245 & 0.960 & 0.316 \\
\hline & Need to control thoughts & 11.34 & 2.84 & 0.773 & 0.266 & 0.825 & 0.504 \\
\hline & Cognitive self-consciousness & 13.05 & 3.23 & 0.424 & 0.275 & 0.937 & 0.344 \\
\hline & Meta-cognitive beliefs (total score) & 52.06 & 8.08 & 0.234 & 0.180 & 0.563 & 0.909 \\
\hline
\end{tabular}

${ }^{*}$ The significance level was 0.05 .

Table 2. Summery of box covariance matrix equality test.

\begin{tabular}{ccccc}
\hline Box & F & DF1 & DF2 & Sig \\
\hline 109.842 & 3.508 & 30 & 92656.078 & 0.001 \\
\hline
\end{tabular}

Table 3. Summery of multivariate test.

\begin{tabular}{|c|c|c|c|c|c|c|c|}
\hline \multirow{2}{*}{ Effect } & & \multicolumn{6}{|c|}{ Multivariate tests } \\
\hline & Tests & Value & $F$ & $D F$ & Error DF & $P$ & ITA Square \\
\hline \multirow[t]{4}{*}{ Groups } & Pilai’s trace & 1.013 & 34.504 & 10 & 336 & 0.001 & 0.0 .507 \\
\hline & Wilk’s lambda & 0.170 & 47.622 & 10 & 334 & 0.001 & 0.588 \\
\hline & Hotelling trace & 3.806 & 63.187 & 10 & 332 & 0.001 & 0.656 \\
\hline & Largest root & 3.498 & 117.541 & 5 & 168 & 0.001 & 0.778 \\
\hline
\end{tabular}

${ }^{* *}$ The significance level was 0.01 . 
Table 4. Test of between-subject effects.

\begin{tabular}{cccccccc}
\hline \multirow{2}{*}{ Source } & \multicolumn{7}{c}{ Between-subject effects } \\
\cline { 2 - 8 } & Dependent Variables & SS & DF1 & DF2 & MS & $F$ & ITA Square \\
\cline { 2 - 8 } Group & Positive beliefs about worry & 2225.839 & 2 & 171 & 1112.920 & $135.337^{* *}$ & 0.613 \\
& Uncontrollability and danger & 2825.184 & 2 & 171 & 1412.592 & $188.153^{* *}$ & 0.688 \\
& Cognitive confidence & 1212.310 & 2 & 171 & 606.155 & $52.525^{* *}$ & 0.381 \\
& Need to control thoughts & 1173.149 & 2 & 171 & 586.575 & $75.617^{* *}$ & 0.469 \\
& Cognitive self-consciousness & 728.701 & 2 & 171 & 364.351 & $39.439^{* *}$ & 0.316 \\
\hline
\end{tabular}

${ }^{* *}$ The significance level was 0.01 .

Table 5. Test of between-subject effects.

\begin{tabular}{ccccccccccccc}
\hline \multicolumn{10}{c}{ Between-subject effects } \\
$\begin{array}{c}\text { Meta-cognitive } \\
\text { subscales }\end{array}$ & $\begin{array}{c}\text { Positive beliefs } \\
\text { about worry }\end{array}$ & $\begin{array}{c}\text { Uncontrollability } \\
\text { and danger }\end{array}$ & $\begin{array}{c}\text { Cognitive } \\
\text { confidence }\end{array}$ & $\begin{array}{c}\text { Need to control } \\
\text { thoughts }\end{array}$ & $\begin{array}{c}\text { Cognitive } \\
\text { self-consciousness }\end{array}$ & Total score \\
\hline Group & $\mathrm{N}$ & OCD & $\mathrm{N}$ & OCD & $\mathrm{N}$ & OCD & $\mathrm{N}$ & OCD & $\mathrm{N}$ & OCD & $\mathrm{N}$ & OCD \\
DEP & $7.51^{* *}$ & -0.138 & $8.37^{* *}$ & -0.328 & $6.46^{* *}$ & $-3.25^{* *}$ & $4.82^{* *}$ & -1.172 & $2.96^{* *}$ & $-2.01^{* *}$ & $8.49^{* *}$ & 0.256 \\
OCD & $7.51^{* *}$ & & $8.70^{* *}$ & & $3.20^{* *}$ & & $6.00^{* *}$ & & $4.98^{* *}$ & & $8.72^{* *}$ \\
\hline
\end{tabular}

DEP: depressed; OCD: obsessive-compulsive; N: normal. ${ }^{* *}$ The significance level was 0.01 .

mean score of the normal group was lower than those of the depressed and obsessive-compulsive groups.

Furthermore, with regard to cognitive confidence and cognitive self-consciousness subscales, there were significant differences between depressed and obsessive-compulsive patients. The mean scores of these two subscales were higher in obsessive-compulsive patient, in comparison with depressed individuals. There was no significant difference between the depressed and obsessive-compulsive groups regarding the three subscales of positive beliefs about worry, uncontrollability and need to control thoughts.

\section{Discussion}

The purpose of this study was to compare the meta-cognitive beliefs and their subscales on the part of depressed, obsessive-compulsive and normal individuals. The mean scores in terms of the meta-cognitive beliefs of the normal group were significantly different from those of the depressed and obsessive-compulsive patients. According to the findings of the present study, the meta-cognitive beliefs of the obsessive-compulsive patients differ from those of the normal group. This is in consistent with the results of previous reports [11] [15]. In addition, in the present study, it was observed that cognitive confidence and cognitive self-consciousness variables were significantly associated with being obsessive-compulsive, and thus, based on these two variables, the obsessive-compulsive disorder of the patients can be predicted. It seems that by increasing the beliefs about cognitive self-consciousness and lack of cognitive confidence, the patients will experience more anxiety and worry. One of the features of obsessive-compulsive disorder is the tendency to concentrate on thinking processes that increase the cognitive self-consciousness and lead to the discovery of unwanted thoughts.

Since obsession is an anxiety disorder, and obsessive patients exhibit a high level of worry, it can be concluded that the uncontrollability of thoughts causes an increase in worry on the part of obsessive patients, and consequently can lead to the persistence of the obsession. According to the results of this study, repetitive obsessive behaviors are related to a lack of cognitive confidence on the part of the patients. Irak and Tosun [16] investigated the role of meta-cognitive beliefs with regard to obsessive-compulsive and worry symptoms. Their findings support the above conclusion.

The results showed that there were significant differences between the mean scores of the subscales with regard to meta-cognitive beliefs in depressed and normal individuals. This is consistent with the results of previous studies by Papageorgiou and Wells [17], Wells [18] and Sadati [19]. Also, the mean scores of two subs- 
cales (cognitive confidence and cognitive self-consciousness) were higher in obsessive-compulsive patient, in comparison with depressed individuals. This is in agreement with the findings of a previous study [20]. The association between cognitive confidence and cognitive self-consciousness, and being obsession-compulsive might be related to the belief that more awareness of thoughts may lead to proper performance, being healthy, and more control over behaviors and situations.

\section{Conclusion}

The results of this study showed that there were significant differences between the meta-cognitive beliefs of the three studied groups involving depressed, obsessive-compulsive and normal individuals. There were significant differences between the mean scores with regard to the meta-cognitive beliefs in normal individuals and in patients with depression or obsessive-compulsive disorders. Furthermore, with regard to cognitive confidence and cognitive self-consciousness subscales, there were significant differences between depressed and obsessivecompulsive patients. The mean scores of these two subscales were higher in obsessive-compulsive patient, in comparison with depressed individuals. There was no significant difference between the depressed and obsessive-compulsive groups regarding the three subscales of positive beliefs about worry, uncontrollability and need to control thoughts. Furthermore, a preventive approach to depression and obsession disorders can be adopted based on information processing and meta-cognitive therapy, through which the efficacy of the therapy can be increased.

\section{References}

[1] Metcalfe, J.E. and Shimamura, A.P. (1994) Metacognition: Knowing about Knowing. The MIT Press, Cambridge.

[2] Efklides, A. and Misailidi, P. (2010) Trends and Prospects in Metacognition Research. Springer, New York. http://dx.doi.org/10.1007/978-1-4419-6546-2

[3] Flavell, J.H. (1979) Metacognition and Cognitive Monitoring: A New Area of Cognitive-Developmental Inquiry. American Psychologist, 34, 906. http://dx.doi.org/10.1037/0003-066X.34.10.906

[4] Wells, A. (1995) Meta-Cognition and Worry: A Cognitive Model of Generalized Anxiety Disorder. Behavioural and Cognitive Psychotherapy, 23, 301-320. http://dx.doi.org/10.1017/S1352465800015897

[5] Wells, A. (2002) Emotional Disorders and Metacognition: Innovative Cognitive Therapy. John Wiley, Chichester. http://dx.doi.org/10.1002/9780470713662

[6] Wells, A. (2009) Metacognitive Therapy for Anxiety and Depression. Guilford Press, New York.

[7] Sadock, B.J., Kaplan, H.I. and Sadock, V.A. (2007) Kaplan \& Sadock’s Synopsis of Psychiatry: Behavioral Sciences/ Clinical Psychiatry. Lippincott Williams \& Wilkins, Philadelphia.

[8] Rachman, S. and de Silva, P. (1978) Abnormal and Normal Obsessions. Behaviour Research and Therapy, 16, 233248. http://dx.doi.org/10.1016/0005-7967(78)90022-0

[9] Borkovec, T.D., Wilkinson, L., Folensbee, R. and Lerman, C. (1983) Stimulus Control Applications to the Treatment of Worry. Behaviour Research and Therapy, 21, 247-251. http://dx.doi.org/10.1016/0005-7967(83)90206-1

[10] Wells, A. and Cartwright-Hatton, S. (2004) A Short form of the Metacognitions Questionnaire: Properties of the MCQ30. Behaviour Research and Therapy, 42, 385-396. http://dx.doi.org/10.1016/S0005-7967(03)00147-5

[11] Shirinzadeh Dastgiri, S., Gudarzi, M.A., Ghanizadeh, A. and Taghavi, S.M.R. (2008) Comparison of Metacognitive and Responsibility Beliefs in Patients with Obsessive-Compulsive Disorder, Generalized Anxiety Disorder and Normal Individuals. Iranian Journal of Psychiatry and Clinical Psychology, 14, 46-55 [in Persian].

[12] Beck, A., Ward, C., Mendelson, M., Mock, J. and Erbaugh, J. (1961) An Inventory for Measuring Depression. Archives of General Psychiatry, 4, 561. http://dx.doi.org/10.1001/archpsyc.1961.01710120031004

[13] Edwards, B.C., Lambert, M.J., Moran, P.W., McCully, T., Smith, K.C. and Ellingson, A.G. (1984) A Meta-Analytic Comparison of the Beck Depression Inventory and the Hamilton Rating Scale for Depression as Measures of Treatment Outcome. British Journal of Clinical Psychology, 23, 93-99. http://dx.doi.org/10.1111/j.2044-8260.1984.tb00632.x

[14] Rachman, S.J. and Hodgson, R.J. (1980) Obsessions and Compulsions. Prentice-Hall, Englewood Cliffs.

[15] Hermans, D., Martens, K., De Cort, K., Pieters, G. and Eelen, P. (2003) Reality Monitoring and Metacognitive Beliefs Related to Cognitive Confidence in Obsessive-Compulsive Disorder. Behaviour Research and Therapy, 41, 383-401. http://dx.doi.org/10.1016/S0005-7967(02)00015-3

[16] Irak, M. and Tosun, A. (2008) Exploring the Role of Metacognition in Obsessive-Compulsive and Anxiety Symptoms. 
Journal of Anxiety Disorders, 22, 1316-1325. http://dx.doi.org/10.1016/j.janxdis.2008.01.012

[17] Papageorgiou, C. and Wells, A. (2001) Metacognitive Beliefs about Rumination in Recurrent Major Depression. Cognitive and Behavioral Practice, 8, 160-164. http://dx.doi.org/10.1016/S1077-7229(01)80021-3

[18] Roussis, P. and Wells, A. (2006) Post-Traumatic Stress Symptoms: Tests of Relationships with thought Control Strategies and Beliefs as Predicted by the Metacognitive Model. Personality and Individual Differences, 40, 111-122. http://dx.doi.org/10.1016/j.paid.2005.06.019

[19] Sadati, S.Z. (2012) The Comparison of Metacognitive Beliefs among Schizophrenic and Depressed Patients with the Ones of Normal Group. Journal of Clinical Psychology, 2, 79-88 [in Persian].

[20] Spada, M.M., Nikčević, A.V., MONETA, G.B. and Wells, A. (2008) Metacognition, Perceived Stress, and Negative Emotion. Personality and Individual Differences, 44, 1172-1181. http://dx.doi.org/10.1016/j.paid.2007.11.010 
Scientific Research Publishing (SCIRP) is one of the largest Open Access journal publishers. It is currently publishing more than 200 open access, online, peer-reviewed journals covering a wide range of academic disciplines. SCIRP serves the worldwide academic communities and contributes to the progress and application of science with its publication.

Other selected journals from SCIRP are listed as below. Submit your manuscript to us via either submit@scirp.org or Online Submission Portal.
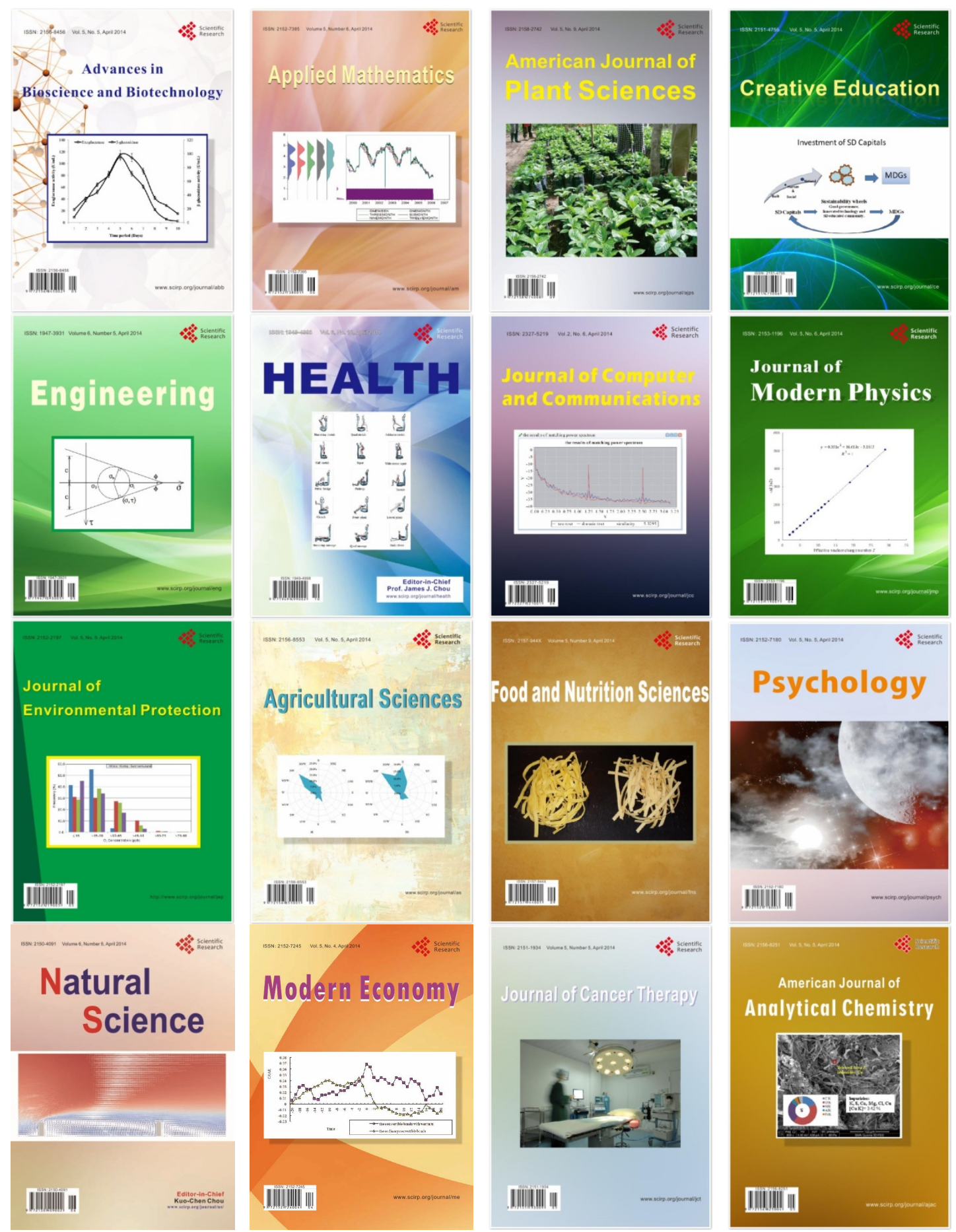